Disponível em

http://www.anpad.org.br/rac

RAC, Rio de Janeiro, v. 16, n. 2, art. 3,

pp. 217-236, Mar./Abr. 2012

$($ (c) EY-No

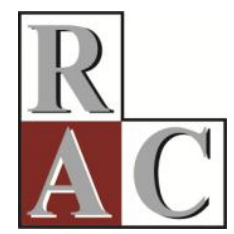

\title{
Relações de Gênero e Subjetividade na Mineração: um Estudo a partir da Fenomenologia Social
}

\author{
Gender Relations and Subjectivity: a Study from Social Phenomenology
}

Fernanda Maria Felicio Macedo*

E-mail: profamacedo@yahoo.com.br Universidade Federal de Ouro Preto - UFOP Mariana, MG, Brasil.

Diego Luiz Teixeira Boava

E-mail: profboava@yahoo.com.br Universidade Federal de Ouro Preto - UFOP Mariana, MG, Brasil.

Monica Carvalho Alves Cappelle

E-mail: edmo@dae.ufla.br Universidade Federal de Lavras - DAE/UFLA Lavras, MG, Brasil.

Maria de Lourdes Souza Oliveira E-mail: julinet@dae.ufla.br Universidade Federal de Lavras - DAE/UFLA

Lavras, MG, Brasil.

* Endereço: Fernanda Maria Felicio Macedo

Rua do Catete, 166, Centro ICSA, Mariana/MG, 35420-000.

Copyright (C) 2012 RAC. Todos os direitos, até mesmo de tradução, são reservados. É permitido citar parte de artigos sem autorização prévia, desde que seja identificada a fonte. 


\title{
Resumo
}

As mulheres vêm ganhando espaço na esfera pública, no que tange ao mercado de trabalho e às representações sociais. Neste cenário, pode-se destacar o setor de extração mineral, que vem aceitando mulheres em toda a sua extensão funcional. Diante disso, pretende-se analisar como se processam as relações de gênero no contexto organizacional de uma empresa de extração mineral. Como referencial, são utilizadas as discussões que pautam o estudo das relações de gênero e subjetividade no universo do trabalho. Já a metodologia de pesquisa se fundamenta na fenomenologia social idealizada por Alfred Schütz. Conclui-se que a mulher na mineração vem conseguindo conquistas, entretanto tais conquistas se devem à sua masculinização, sem existência de respeito e valorização das diferenças. A legitimação do trabalho feminino somente ocorre quando este está adequado aos padrões de desempenho masculino. Dessa forma, o presente estudo se faz relevante em sua contribuição para as pesquisas científicas sobre gênero, ao estudar as relações entre homens e mulheres em um ambiente com características tão singulares quanto o da mineração. No mais, no trabalho apresenta-se como diferencial o emprego da fenomenologia social na pesquisa sobre gênero, podendo servir de aporte para investigações vindouras.

Palavras-chave: gênero; subjetividade; fenomenologia social; mineração.

\begin{abstract}
Women are gaining space in the public sphere, in relation to the labor market and social representations. In this context, the mineral extraction sector stands out, as it has been accepting women in all its functional extensions. Given this, we intend to analyze the process of gender relations in the organizational context of a mining company. Discussions that guide the study of gender relations and subjectivity in work are used as reference. Research methodology is based on social phenomenology as conceived by Alfred Schütz. We conclude that women have managed gains in the mining industry, but these achievements are due to masculinization, as in fact there is no respect and appreciation for their differences. The legitimacy of women's work occurs only according to existing standards of male performance. Thus, this work is relevant in its contribution to scientific research on gender, and to study the relationships between men and women in an environment with such unique characteristics as the mining industry. In addition, the work features a unique use of phenomenology in social research on gender and might serve as a reference for future investigations.
\end{abstract}

Key words: gender; subjectivity; social phenomenology; mining. 


\section{Introdução}

$\mathrm{Na}$ sociedade contemporânea, as mulheres vêm ganhando espaço na esfera pública, no que tange ao mercado de trabalho, e nas representações políticas. O movimento pela emancipação do sexo feminino tem suas origens no século XX, e processou-se de diversas formas nos contextos mundial e nacional. Tal movimento acabou por aprofundar as discussões sobre a questão do homem e da mulher na sociedade, permitindo constatar que tal questão transcende as diferenças biológicas entre os sexos, ou seja, existe uma construção social de masculinidade e feminilidade. Neste contexto, emerge o conceito de gênero, propondo que o vocábulo sexo somente passe a ser empregado ao se falar de diferenças biológicas entre homens e mulheres, e gênero, quando se faz referência às estruturas sociais, culturais ou psicológicas que se impõem a essas diferenças biológicas.

Para Soihet (1998), gênero é um termo utilizado desde a década de 1970 para ir além da diferença sexual, pois sublinha o aspecto relacional entre mulheres e homens, ou seja, nenhuma compreensão de qualquer um dos dois pode existir por meio de um estudo que os considere totalmente em separado. Assim, para a autora, o gênero é um meio de compreender relações complexas entre as diversas formas de interação humana.

Considerando-se essa contextualização, tem-se a seguinte problemática de pesquisa: como se processam as relações de gênero no contexto organizacional de uma empresa de extração mineral? Pretende-se analisar como homens e mulheres se relacionam em um contexto organizacional marcado pelo predomínio histórico de trabalhadores masculinos. Sabe-se que a mineração é uma atividade socialmente reconhecida como mais adequada a homens (Quirino, 2010).

Para Hirata (2002), no setor produtivo, as profissões que exigem força física e trabalhos pesados, realizados em ambientes inóspitos, sujos e insalubres, geralmente são associadas a estereótipos masculinos, visto que requerem coragem e determinação; ao passo que a feminilidade é associada ao trabalho leve, fácil, limpo, que exige paciência e minúcia, o que caracteriza a divisão sexual do trabalho. Assim, como referencial teórico, são discutidas as questões que pautam o estudo das relações de gênero e subjetividade no universo do trabalho.

Fundamenta-se, por sua vez, a metodologia de pesquisa com base na fenomenologia social idealizada por Alfred Schütz (1972), na qual se analisa a intersubjetividade do ser humano no mundo da vida. Como método que se ocupa das relações entre as pessoas, constitui objeto de interesse nesta pesquisa, na medida em que se objetiva analisar as relações estabelecidas entre homens e mulheres na empresa mineradora lócus de pesquisa.

A coleta de dados realizou-se com a colaboração de nove sujeitos de pesquisa, funcionários da empresa em estudo, dos quais cinco mulheres e quatro homens, que desempenham funções operacionais e de gestão. Esses funcionários discorrem na forma de relato de experiência sobre questões estruturadas, que visam a nortear o depoimento com base no foco de pesquisa. A análise de dados se dá a partir da abordagem fenomenológica de Sanders (1982), a mais empregada quando se usa como referencial metodológico a fenomenologia social.

O trabalho se estrutura com a apresentação de uma revisão da literatura sobre as relações de gênero e subjetividade sob a ótica da divisão sexual do trabalho. Na sequência, tem-se a apresentação da trajetória metodológica seguida para elaboração da pesquisa, com especial atenção à fenomenologia social. Por fim, discutem-se os resultados.

Este trabalho constitui relevante contribuição para as pesquisas científicas sobre gênero, pois contém estudo sobre as relações entre homens e mulheres em um ambiente com características tão singulares quanto o da mineração. Além disso, no trabalho, apresenta como diferencial o emprego da fenomenologia social na pesquisa sobre gênero, podendo servir de aporte para investigações vindouras. 


\section{Relações de Gênero e Subjetividade}

Segundo Beauvoir (1949), a mulher se configura como sexo secundário, criado a partir de Adão, deixando-se dominar, na medida em que aceita e internaliza a condição de mulher mãe, esposa, dócil, prendada, meiga, compreensiva, ou seja, passa a ser apenas uma mulher dotada de feminilidade. $\mathrm{O}$ homem é o sujeito absoluto e a mulher, o outro. O pano de fundo que permite e sustenta essa dominação é o patriarcado.

Outro elemento que justifica tal aceitação e internalização da submissão por parte da mulher é apontado por Priore (2006) como a crença no amor. A sensibilidade da mulher é um dos aspectos que a torna dependente e, portanto, passível de ser dominada pelos homens. Saffioti (2004), por sua vez, afirma que não há vítima passiva, e, com o tempo, ela tende a reagir por meio do questionamento da realidade imposta.

Tal reação, fundamentada na eclosão de movimentos feministas ao longo do século XX e, mais precisamente, o desenvolvimento de trabalhos sobre gênero na década de setenta, combatendo a invisibilidade da mulher na história da humanidade, acabou por ocasionar algumas mudanças no contexto social de atuação da mulher contemporânea.

Esta passou a atuar, além da esfera privada, no espaço público, tornando-se presente no mercado de trabalho, nas representações políticas e sociais. Novo (2003), ao tentar descrever a situação da mulher na atualidade, afirma que elas conquistaram espaço na vida pública, criaram um nicho feminino, contudo, não lograram êxito ao tentar redefinir as regras do jogo, pois a soberania ainda permanece masculina. $\mathrm{O}$ trabalho feminino não alcançou a igualdade de gênero por completo, $\mathrm{o}$ patriarcado permanece sob o paradigma androcêntrico, ou seja, todos os acontecimentos continuam centrados na figura masculina.

Neste cenário, o avanço das mulheres no tocante à atuação no ambiente de trabalho é gradual, não conseguindo romper os aspectos que fundamentam o patriarcado. Entre esses, a divisão sexual do trabalho se destaca, na medida em que justifica socialmente as tarefas que podem ser desenvolvidas por homens e mulheres.

Para Hirata e Kergoat (2007), o termo divisão sexual do trabalho aplica-se a duas acepções de conteúdos distintos. Trata-se, por um lado, de uma acepção sociográfica: estuda-se a distribuição diferencial de homens e mulheres no mercado de trabalho, nos ofícios e nas profissões, e as variações no tempo e no espaço dessa distribuição; e, por outro, analisa-se como ela se associa à divisão desigual do trabalho doméstico entre os sexos.

Hirata (2002) efetua ainda uma crítica à divisão sexual do trabalho, que associa aos homens a execução de trabalhos nobres e, às mulheres, o desempenho de tarefas periféricas. Além disso, ainda em dias atuais, desvaloriza a mulher, mesmo com o advento de novas tecnologias. Em relação aos estudos organizacionais, a autora chama também a atenção para realização de pesquisas blindadas de gênero, que consideram a trabalhadora como simples sinônimo do trabalhador, ou seja, como se os trabalhadores e as demandas relacionadas ao trabalho masculino e ao feminino tivessem as mesmas características.

Ainda nessa discussão, tem-se o ambiente doméstico, em que se analisa a divisão sexual do trabalho relacionada à invisibilidade do trabalho das mulheres. Hirata e Kergoat (2007) chamam a atenção ao afirmarem que, na discussão sobre a divisão sexual do trabalho, necessariamente, deve ser considerada a divisão do trabalho doméstico. Já em termos de mercado de trabalho, o estudo da divisão sexual deste passa pela analise de ações que sustentam o fenômeno do teto de vidro.

$\mathrm{O}$ conceito de teto de vidro aponta para uma sutil e transparente barreira que impossibilita às mulheres a ascensão a níveis organizacionais mais elevados. Essa é uma manifestação das desigualdades de gênero. Para Steil (1997), muitas pesquisas acerca dessa questão dentro da 
administração tendem a negligenciar a realidade de discriminação e redução das oportunidades das mulheres no campo das organizações.

Steil (1997, p. 63) esclarece ainda que "o fenômeno do teto de vidro é caracterizado pela pervasividade (presente e percebida em todos os lugares)". As mulheres não recebem as mesmas oportunidades de crescimento que os homens em muitas organizações. Além disso, seu papel social de mãe e dona de casa faz com que as corporações julguem que o homem pode apresentar maior comprometimento organizacional com a empresa, devendo, portanto, ocupar os cargos mais elevados.

O fenômeno do teto de vidro favorece o surgimento e a manutenção de relações assimétricas entre homens e mulheres nas organizações. Vale destacar que a divisão sexual do trabalho, refletida no ambiente organizacional, acaba por gerar também impactos ligados à relação de poder entre homens e mulheres.

Cappelle, Melo, Brito e Brito (2004), tratando das relações de gênero e poder em organizações, afirmam que os homens e mulheres atuam no espaço organizacional por meio de ações de negociação, contestação e luta, considerando os interesses em jogo.

Os autores defendem a existência de circuitos de poder originados das relações sociais entre homens e mulheres. E tais circuitos são passíveis de transformação e podem se manifestar em três níveis: o primeiro nível representa as relações mais aparentes de poder, como ordens e punições; já o segundo é constituído pelo conjunto de normas e procedimentos do espaço organizacional, envolvendo linguagem, modos de vestir, códigos de conduta; e o terceiro trata da introdução de inovações em técnicas de gestão e produção, capazes de influenciar as relações sociais no ambiente organizacional.

Por sua vez, Gherardi e Poggio (2001), ao examinarem a dinâmica organizacional responsável pela manutenção das assimetrias de gênero nas organizações, apontam que as desigualdades de gênero nestas se devem a práticas culturais e sociais. Tais práticas ainda são os principais mecanismos que fazem com que a desigualdade permaneça e seja dificil de se combater.

Nesse cenário de assimetria de gênero, homens e mulheres se relacionam com base na subjetividade, em que cada um significa esse processo considerando suas respectivas experiências de vida. Logo, um caminho promissor para o estudo das relações de gênero está ligado à investigação da subjetividade do homem e da mulher, manifestada nessas relações.

Portanto, as abordagens sobre as relações de gênero nas organizações à luz da divisão sexual do trabalho corroboram, no limite dessa investigação, ao sustentar a existência de assimetria de gênero no ambiente organizacional, seja em função da própria sociedade, cultura, patriarcado, capitalismo e/ou jogos de interesses. Todavia, há ainda necessidade de aprofundamento das teorias no tocante às formas de modificação efetiva dessa divisão que privilegia homens em detrimento de mulheres.

A partir desta orientação teórica apresenta-se no tópico seguinte a trajetória metodológica empregada para o desenvolvimento da investigação proposta.

\section{Trajetória da Pesquisa}

\section{Sobre o método}

Alfred Schütz busca estabelecer os fundamentos de uma sociologia fenomenológica. Para isso, o autor utilizou a obra fenomenológica de Husserl a fim de aprofundar a sociologia da compreensão desenvolvida por Max Weber. 
Os trabalhos de Alfred Schütz baseiam-se no pressuposto inicial de que o homem vive no mundo do senso comum ou da vida, relacionando-se com outros homens. Para Schütz (1979), o mundo da vida cotidiana:

significa o mundo intersubjetivo que existia muito antes do nosso nascimento, vivenciado e interpretado por outros, nossos predecessores, como um mundo organizado. Ele agora se dá à nossa experiência e interpretação. Toda interpretação desse mundo se baseia num estoque de experiências anteriores dele, as nossas próprias experiências e aquelas que nos são transmitidas por nossos pais e professores, as quais, na forma de "conhecimento à mão", funcionando como um código de referência (Schütz, 1979, p. 72).

O homem vive neste mundo em uma constante atitude natural, ou seja, sempre adota uma postura mental de que as coisas são tidas como pressupostos.

Schütz (1972) aponta a existência de quatro tipos de alter ego na sociedade, a saber:

- Predecessores - pessoas que existiram em uma realidade passada. Somente tomamos consciência de sua existência por leituras ou relatos.

. Contemporâneos - pessoas que estão vivas na mesma realidade temporal.

. Consócios - pessoas que convivem diretamente, na mesma realidade temporal e espacial.

- Sucessores - pessoas que viverão após a morte dos contemporâneos e permanecerão anônimas para esses indivíduos para sempre.

Entre esses tipos de pessoas, destacam-se os contemporâneos e consócios, pois somente esses são capazes de estabelecer um relacionamento Nós e vivenciarem uma situação face a face. Esses termos foram cunhados por Schütz (1972) e advêm do fato de a consciência do ser desenvolver orientações para o tu (alter ego), ou seja, em sua forma pura, as orientações para o tu surgem da captação por uma pessoa da existência de outra em interações face a face. Assim, se a orientações para o tu de uma pessoa é correspondida por outra, se ambas intencionalmente se voltam uma para outra, resulta daí um relacionamento Nós. O envolvimento face a face com os outros é a principal forma de encontros sociais.

Tal envolvimento, geralmente, ocorre quando duas pessoas compartilham a mesma comunidade de espaço e tempo, em suma, é a consciência da presença do outro. Devido a isso, ocorre a simultaneidade da vida, pela qual um ser pode experienciar o fluxo de pensamento do outro. Esse conceito de simultaneidade se deve ao fato de o homem só poder atribuir significado à sua ação passada ou futura, já que, no presente, cabe a ele observar as vivências dos demais quando ocorrem de verdade. Ao ser humano cabe esperar que suas ações transcorram para poder refletir sobre elas no passado. Para Schütz (1979), ninguém pode se ver em ação, assim como tampouco pode conhecer o estilo de sua própria personalidade.

Dessa forma, Schütz (1979) afirma que o mundo social ou da vida é intersubjetivo, comum a todos os homens. Nesse mundo, o homem se relaciona e confere significado a sua ação. A ação no cotidiano é delineada como ação social quando o ator a direciona para outras pessoas, as quais ele vislumbra como seres conscientes.

Logo, a fenomenologia social consiste em uma orientação metodológica que muito tem a contribuir para o estudo das relações de gênero, que consideram o homem e a mulher como seres relacionais.

Alem disso, na fenomenologia social, considera-se o processo de significação que o ser humano atribui a sua ação. Isso pode ser muito pertinente, já que se investigam as relações de gênero em um ambiente organizacional, no qual o sujeito atribui sentido ao seu trabalho. 
Sob a ótica fenomenológica social, homens e mulheres serão investigados como consócios e/ou contemporâneos em um relacionamento nós. Ou seja, pesquisa-se o homem e a mulher em um dado ambiente de trabalho considerando a simultaneidade da vida, ambos experienciando o fluxo de pensamento um do outro em uma situação face a face.

Ou seja, na fenomenologia social, abordam-se as relações de gênero pelo estudo do homem e da mulher se relacionando por meio de encontros face a face que abarcam noções de tempo e espaço (consócios e contemporâneos), relacionamento nós, simultaneidade da vida, fluxo de pensamento.

\section{Delineamento}

Este trabalho é estruturado com base em uma abordagem qualitativa, uma vez que o interesse de pesquisa encontra-se no processo e na forma de como o fenômeno se manifesta. Além de qualitativo, apresenta cunho exploratório.

Nesse sentido, os fenômenos que não se prestam a uma fácil quantificação são os mais apropriados para ser analisados por procedimentos da pesquisa qualitativa que, segundo Martins e Bicudo (1989), busca, diferentemente da pesquisa quantitativa, uma compreensão particular daquilo que se estuda. Aqui não há preocupação com generalizações e leis, sendo que o foco da atenção é centralizado no específico, no peculiar, no individual, almejando sempre a compreensão.

O tratamento qualitativo consiste em um conjunto de diferentes técnicas interpretativas que visam descrever e decodificar os componentes de um sistema complexo de significados.

Para Gibbs (2009), apesar de existirem muitos enfoques qualitativos, é possível identificar as seguintes características em comum: análise da experiência de indivíduos ou grupo; exame das interações e comunicações que permeiam o objeto de estudo; investigação de documentos ou traços semelhantes de experiências ou interações.

Flick (2009) afirma que a pesquisa qualitativa se baseia em atitudes específicas de abertura para quem e o quê está sendo estudado, de flexibilidade para abordar um campo em lugar de projetar uma estrutura naquilo que se estuda, e assim por diante. O emprego da perspectiva qualitativa neste trabalho se deve a essa atitude flexível perante o objeto de investigação.

Vale ressaltar que a pesquisa ainda constitui um estudo de caso. Segundo Triviños (1987), no estudo de caso, os resultados são válidos só para o caso que se estuda. Não se pode generalizar o resultado atingido no estudo de um hospital, por exemplo, a outros hospitais. Mas, nesse ponto, encontra-se o grande valor do estudo de caso: fornecer um conhecimento aprofundado de uma realidade delimitada. Portanto, é evidente que a pretensão deste estudo não é propor a generalização de seus resultados, mas sim uma análise detalhada de uma realidade.

\section{Lócus de pesquisa}

A presente pesquisa é desenvolvida em uma empresa de extração mineral atuante no Quadrilátero Ferrífero, em Minas Gerais. Assim, a atividade principal dessa organização está ligada à retirada de minérios do meio ambiente.

Em termos de constructo social, esse processo de mineração é visto como um trabalho inerente ao homem, já que exige força física, resistência, objetividade, entre outras competências ditas masculinas.

Neste cenário, o domínio do fazer masculino é marcante, constituindo, portanto, um lócus de pesquisa promissor quando se pretende investigar as relações que emergem ao mulheres adentrarem nesse ambiente de trabalho tão reservado à virilidade masculina. 
A inserção da mulher na atividade de mineração se processa mais efetivamente em função dos avanços tecnológicos, que lhes permitem conquistar espaço nas áreas administrativas e, principalmente, operacionais. Além da variável tecnologia, a mulher na mineração teve que enfrentar questões ligadas aos hábitos culturais, pois, segundo Castilhos e Castro (2006), a tradição e a superstição presentes em diversas comunidades mineradoras do mundo consideram a presença da mulher nas minas um fator de má sorte.

Em termos de pesquisa e documentação estatísticas, a trabalhadora na mineração é considerada invisível, pois, no limite dessa investigação, foram encontrados poucos estudos sobre mineração considerando o gênero. Desses, a maior parte se ocupa de temas como produtividade, relação com o meio ambiente, estrutura funcional, entre outros assuntos de ordem mais técnica.

Todavia, pelos dados constantes na Tabela 1, tem-se a indicação de que a realidade da mineração está sendo transformada em função do aumento da participação da mulher no processo de extração mineral.

Tabela 1

\section{Pessoas Empregadas por Gênero}

\begin{tabular}{cccc}
\hline Setor/Gênero & $\mathbf{2 0 0 5}$ & $\mathbf{2 0 0 6}$ & $\mathbf{2 0 0 7}$ \\
\hline Extrativo Mineral (total) & 147.560 & 183.188 & 185.444 \\
Masculino & 134.746 & 165.451 & 167.473 \\
Feminino & 12.814 & 17.737 & 17.971 \\
\hline
\end{tabular}

Nota. Fonte: Quirino, R. (2010, abril). Divisão sexual do trabalho e gênero na mineração. Anais do Congresso Iberoamericano de Ciência, Tecnologia e Gênero, Curitiba, PR, Brasil, 8. p. 4.

O número de mulheres que trabalham nessa empresa, entre o total de empregados, (aproximadamente dois mil), segundo dados de novembro de 2010, está em 6\% para 94\% de homens. E, apesar desses percentuais caracterizarem uma baixa participação de mulheres na mineração, a empresa informou que esse número vem crescendo nos últimos anos, constituindo um processo gradual de avanço da mulher no universo masculinizado.

\section{Procedimentos de coleta de dados}

O processo de seleção dos sujeitos de pesquisas na abordagem qualitativa visa a equilibrar casos regulares e discrepantes, não se objetivando, com este estudo, conforme mencionado, fazer uma generalização dos resultados.

De acordo com Minayo (1998, p. 43), a pesquisa qualitativa não pode se basear no critério numérico, para poder garantir representatividade. A amostragem ideal é aquela que possibilita abranger a totalidade do problema investigado em suas múltiplas dimensões.

Diante disso, os seguintes funcionários foram convidados a participar da pesquisa: dez da área operacional e quatro da área gerencial de operações. Eles foram selecionados pelo critério de conveniência dos pesquisadores, critério esse associado ao perfil dos cargos que ocupavam:

Auxiliar de Serviços Gerais, que envolve a limpeza das áreas internas e externas da empresa, geralmente, desempenhado por mulheres;

Mecânico de equipamentos, que desenvolve tarefas ligadas à manutenção preventiva e corretiva de máquinas e veículos utilizados na empresa, uma profissão estereotipada como masculina;

- Operador de Equipamentos, que dirige caminhões fora da estrada, isto é, dentro da mina, tarefa também atribuída a homens; 
- Analista, que trabalha detectando e calculando os riscos envolvidos na extração de minérios para o meio ambiente, levando em consideração as condições topográficas. Função significada como masculina;

- Gerente de área, que coordena todas as atividades desempenhadas em um setor da extração mineral, atividade predominantemente masculina.

Opta-se por estudar relações de gênero na área de operações da empresa, porque ela apresenta funções restritas para mulheres, já que são significadas socialmente como masculinas. Em função disso, a maior parte das mulheres da empresa trabalha no setor administrativo, e a única tarefa operacional vista como feminina é o trabalho em serviços gerais.

$\mathrm{Na}$ coleta de dados, solicita-se aos sujeitos de pesquisa discorrer sobre proposições na forma de relato de experiência, que consiste na descrição escrita de uma experiência vivida. A opção pela escrita em detrimento da fala se justifica na medida em que Ricoeur (1988) demonstra que a passagem do discurso à escrita é a passagem do dizer ao dito. O texto apresenta uma vida própria, que pode se desviar daquilo que o locutor queria dizer, sendo uma espécie de objetivação do discurso, em virtude de ter perdido as características subjetivas do locutor. Assim, há uma libertação das palavras do indivíduo que escreve, quando da leitura por outrem. O indivíduo que escreve contribui com as palavras e o leitor com a significação.

Sob a ótica da fenomenologia social, quando o indivíduo escreve sobre algum tema, esse assunto acessa diretamente a sua consciência, passando a descrever racionalmente sua experiência vivida. No presente trabalho, essa experiência liga-se com o relacionamento nós, estabelecido em encontros face a face entre homens e mulheres no cotidiano da mineração. Através da reflexão para elaboração de um relato escrito, os sujeitos de pesquisa acessam a significação que atribuem a essas relações de gênero.

As proposições para orientação da elaboração dos relatos são apresentadas nas Tabelas 2 e 3:

\section{Tabela 2}

\section{Proposições de Pesquisa para Mulheres}

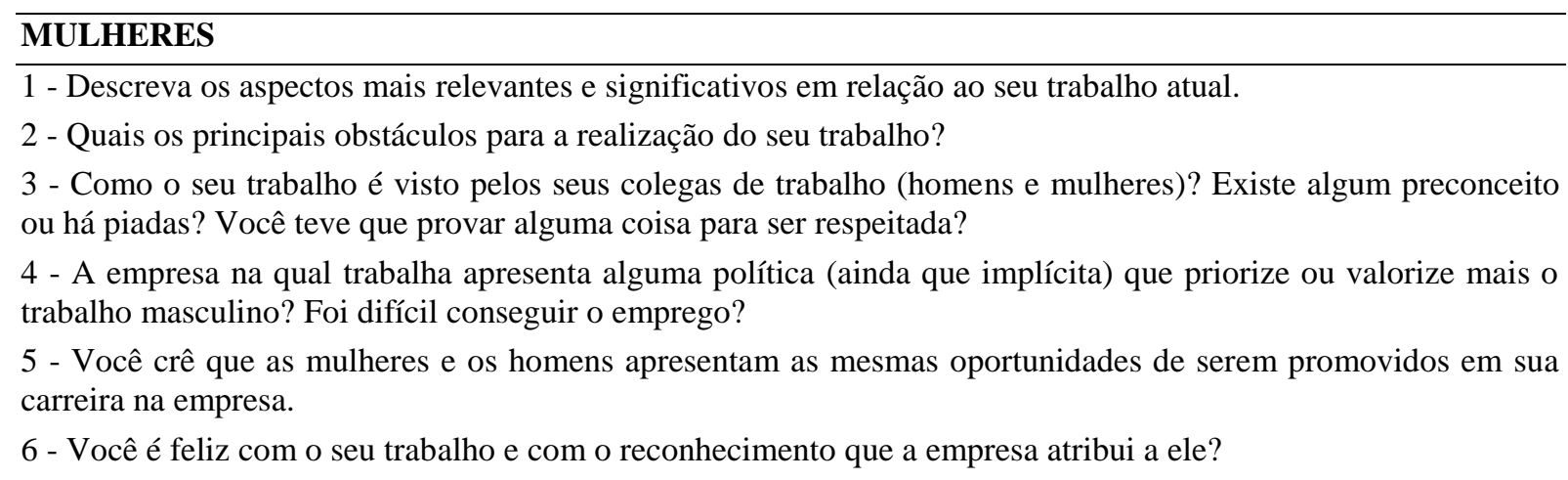

Nota. Fonte: Elaborado pelos autores. 
Tabela 3

\section{Proposições de Pesquisa para Mulheres}

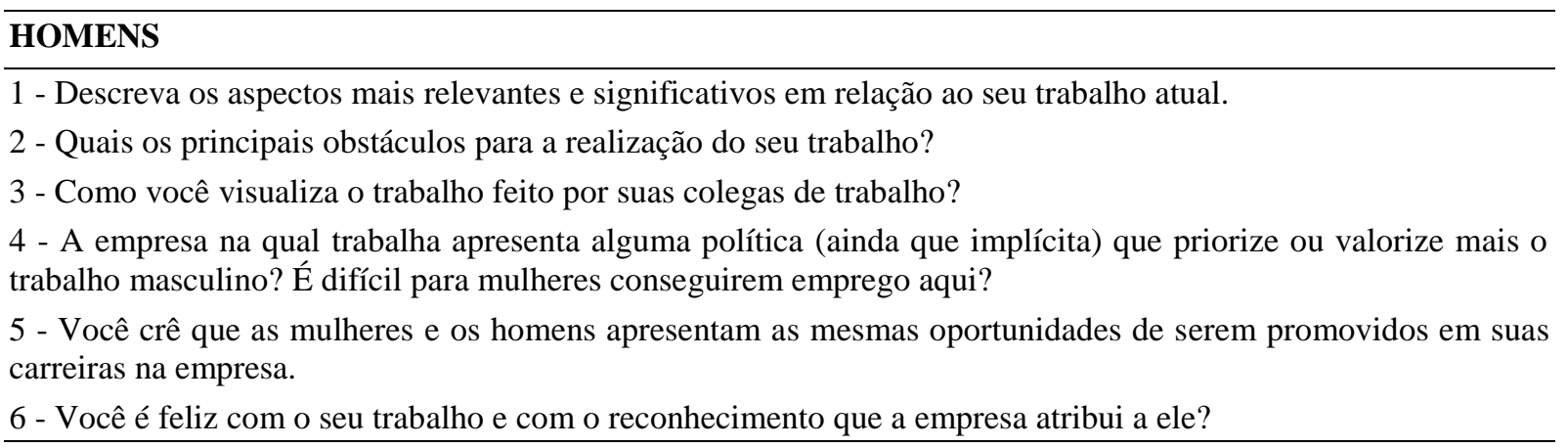

Nota. Fonte: Elaborado pelos autores.

Obteve-se o retorno de nove relatos entre os 14 distribuídos. Entre esses, citam-se: um homem auxiliar de serviços gerais, dois mecânicos de equipamentos, duas mulheres operadoras de equipamentos, um homem operador de equipamentos, duas analistas e uma gerente de área.

\section{Procedimentos de análise de dados}

A interpretação dos dados coletados ocorre em três momentos distintos.

1. Na fase de observação empírica dos sujeitos de pesquisa.

2. Durante a leitura dos relatos.

3. Na elaboração das análises e da síntese.

Nestes momentos, emprega-se a abordagem fenomenológica de Sanders (1982), atentando-se para prática da redução fenomenológica por parte do pesquisador.

Para Sanders (1982), existem três componentes fundamentais para a estrutura fenomenológica de pesquisa, a saber:

1. Determinação dos limites de do que e de quem deve ser investigado: os objetos de pesquisa mais comuns à abordagem fenomenológica são os fenômenos que não se prestam à quantificação. No tocante ao quem investigar, Sanders (1982) aponta para o fato de que o pesquisador deve aprender a trabalhar em profundidade com um reduzido número de sujeitos, pois nem sempre a quantidade destes significa riqueza de informações. Nessa fase, o pesquisador acumula conhecimentos sobre o seu objeto de pesquisa e sobre aquilo que o cerca. Isso significa uma abertura da consciência para o fenômeno;

2. Coleta de dados: deve proceder por meio de entrevistas ou relatos;

3. Análise fenomenológica dos dados: deve ocorrer com base na observância dos seguintes procedimentos:

- Descrição do fenômeno tal qual está apresentado nos relatos.

- Identificação dos temas que emergem dos relatos. O que identifica um tema são sua importância e centralidade, e não a frequência com que aparece no discurso. Ressalta-se que a fenomenologia permite a identificação do dito pelo não dito, ou seja, há temas que podem ser inferidos pelo pesquisador. 
- Junção dos temas em unidades de significação ou sentido, que irão caracterizar a estrutura significativa do fenômeno.

Neste trabalho, os relatos de homens e mulheres serão analisados individualmente e, em um segundo momento, comparados.

Sanders (1982) ressalta que todo o processo de análise dos dados deve ser pautado na execução da redução fenomenológica, que consiste na busca do fenômeno, livre de traços pessoais e culturais, o que levará à obtenção da essência. Segundo Merleau-Ponty (1994), a redução se dá não para nos afastarmos do mundo em direção à consciência, ao eu puro, mas sim porque, sendo do mundo, temo-lo como tão evidente e real, que ele acaba por passar sem ser notado.

Assim, a redução fenomenológica consiste em suspender o juízo sobre a existência ou não existência do fenômeno (corresponde à suspensão momentânea da faculdade de avaliar), para verificação desse fenômeno sob nova perspectiva. Assume-se uma atitude neutra, visando refletir e questionar, de forma que possibilite apreender novo sentido sobre fatos que não tinham sido vistos e observados anteriormente.

A redução faz com que os sentidos menos aparentes contidos nos relatos possam emergir. Essa redução é uma tentativa de minimizar, e não de acabar com os efeitos da subjetividade do pesquisador nos resultados logrados.

Dessa forma, a fenomenologia prevê a inesgotabilidade dos sentidos, ou seja, as unidades extraídas dos relatos somente existem em função da ótica do pesquisador que efetua a análise.

Não há um único sentido correto a emergir do texto, mas vários e inesgotáveis sentidos, que podem variar de acordo com a perspectiva do sujeito investigador. Essa inesgotabilidade na fenomenologia não diminui a validade dos resultados, mas, sim, permite que esses sejam continuamente aprofundados, pois o estudo da realidade não é estático, mas sim dinâmico.

Os relatos dos sujeitos de pesquisa são analisados mediante esta metodologia. Primeiramente, ocorre uma análise separada dos relatos e, posteriormente, uma análise coletiva. Isso se dá para favorecer o aprofundamento da investigação.

\section{Apresentação e Análise dos Dados}

\section{Unidades de sentido}

No presente tópico, trata-se da apresentação das unidades de sentido identificadas com base na análise fenomenológica dos dados. Conforme mencionado, tem-se inicialmente a apresentação das unidades extraídas dos relatos efetuados por homens e, na sequência, a das unidades de sentido ligadas aos relatos de mulheres. A análise ocorre primeiramente de forma individual e, posteriormente, relacional.

A partir da análise fenomenológica dos relatos masculinos, evidenciam-se quatro unidades de sentido: (a) Relação com o Trabalho; (b) Trabalho Coletivo; (c) Presença da Mulher; (d) Ausência de Percepção da Discriminação de Gênero.

Para exposição dos dados categorizados, apresentam-se frases dos relatos de experiência. 
Tabela 4

Unidade de Sentido I - Relação com o Trabalho

\begin{tabular}{lc}
\hline Frases & Sujeitos \\
\hline "Busco realizar manutenção de equipamentos de Mina em tempo hábil e com segurança, vencendo & H01 \\
condições climáticas e materiais". & H02 \\
"Procuro gostar daquilo que faço, mas ainda não sou devidamente reconhecido". & H03 \\
"Sou feliz porque tenho algumas prioridades e os superiores e encarregados são tranquilos, mas o & \\
trabalho é repetitivo. É visto, mas não dá valor algum”! & \\
"Eu sou bastante feliz no que exerço dentro da empresa, cada dia que passa você aprende várias \\
coisas novas sobre o equipamento que está dando manutenção. A empresa poderia ser mais \\
reconhecida no trabalho e que faço na manutenção dando mais treinamentos sobe os equipamento, \\
dando oportunidades para conhecer outros locais de trabalho como outras minas que à pertencem, \\
fazer visitas nas fábricas de equipamentos para podermos ficar mais integrados no que estamos \\
exercendo na nossa função dentro da empresa".
\end{tabular}

Nota. Fonte: Relatos de experiência elaborados pelos sujeitos de pesquisa.

Nessa unidade de sentido, evidencia-se que os homens sujeitos da pesquisa apresentam uma relação com o trabalho satisfatória. Em sua descrição, gostam da atividade que realizam, mas encontram fatores no ambiente de trabalho que podem ser melhorados, como: oferta de cursos, reconhecimento e dinamização do trabalho repetitivo. A relação para com o trabalho é racional e utilitarista, na medida em que este lhe serve como meio para atingir outros fins.

Tal unidade remete ao referencial do significado social do trabalho masculino ligado à questão de provimento da família. O homem trabalha para sustentar sua mulher e filhos, sendo, assim, uma figura central e com poder de decisão sobre a vida daqueles que se encontram sob sua responsabilidade. Tal interface entre o homem, o trabalho e a família consiste no sustentáculo da sociedade patriarcal.

Tabela 5

\section{Unidade de Sentido II - Trabalho Coletivo}

\begin{tabular}{lc}
\hline Frases & Sujeitos \\
\hline "Todos trabalham para que nenhum sobrecarregue o outro - coletividade". & H01 \\
"Eu respeito o trabalho dos meus colegas". & H02 \\
"o diálogo em equipe para debater e trocar ideias sobre o trabalho a ser executado". & H04 \\
\hline
\end{tabular}

Nota. Fonte: Relatos de experiência elaborados pelos sujeitos de pesquisa.

A questão do trabalho coletivo é significada pelos homens como realidade benéfica e positiva que eles sempre encontram no cotidiano de seu trabalho. Evidencia que os sujeitos creem que seu trabalho é fruto de uma ação conjunta e do companheirismo estabelecido entre os parceiros.

Nessa unidade, observa-se que, pela construção social de masculinidade, o homem pode e deve trabalhar em conjunto com outros homens, já que representam igual papel social de provedores, caracterizados pela força física e pela racionalidade. Nesse contexto, quando um homem se relaciona com outro, geralmente, não precisa provar que é capaz de desempenhar nenhuma tarefa ou ação. Os homens se significam como iguais. 
Tabela 6

\section{Unidade de Sentido III - Presença da Mulher}

\begin{tabular}{lc}
\hline Frases & Sujeitos \\
\hline "As mulheres chegaram aos poucos". & H01 \\
"Temos mulheres trabalhando em todas as áreas da empresa". & H02 \\
"Isto pode variar de um setor para outro, tem áreas que são mais valorizadas o trabalho masculino \\
como o de mecânico, tem outras áreas que podem ser mesclado o trabalho masculino e feminino \\
por ser uma área mais leve de trabalhar. Na área de manutenção, é muito difícil as mulheres \\
conseguirem uma vaga para trabalhar. Já numa área mais administrativa é mais fácil de ser \\
contradada".
\end{tabular}

Nota. Fonte: Relatos de experiência elaborados pelos sujeitos de pesquisa.

Nessa unidade, observa-se que, para os sujeitos de pesquisa, as mulheres chegaram ao ambiente organizacional. Todavia, as funções que irão desempenhar estão associadas às concepções de gênero e divisão sexual e social do trabalho, no qual a mulher desempenha tarefas leves e de organização, enquanto o homem atua em tarefas ligadas à virilidade.

A discussão sobre trabalho leve versus trabalho pesado permeia o estudo das relações de gênero de forma central. Isso uma vez que a associação de trabalho leve, com tarefas ou ações de menor importância ou significado, contrapõe-se à do trabalho pesado, empreendido por homens, como significativa e relevante.

Assim, as mulheres chegam à organização para fazerem trabalhos que, em sua maior parte, não são próprios da construção social de masculinidade e, portanto, não ameaçam os homens. A presença da mulher pode ser descrita, assim, como interessante e necessária para fazer tarefas não ligadas ao padrão de masculinidade.

Tabela 7

\section{Unidade de Sentido IV - Ausência de Percepção da Discriminação de Gênero}

\begin{tabular}{lc}
\hline Frases & Sujeitos \\
\hline "Não, temos mulheres mecânicas e eletricistas trabalhando em conjunto". & H01 \\
"e, são igualmente respeitadas". & H02 \\
"Elas ficam um pouco restritas em alguns serviços que terão que executar por serem bastante \\
pesado, aí elas tem que fazer alguma ordem de serviço mais leve para poder executar de uma \\
forma mais tranquila".
\end{tabular}

Nota. Fonte: Relatos de experiência elaborados pelos sujeitos de pesquisa.

Nessa unidade de sentido, os sujeitos de pesquisa percebem que as mulheres são tratadas de forma igualitária aos homens, na medida em que desempenham tarefas leves. Assim, mesmo que a mulher esteja desempenhando uma função predominantemente masculina, como mecânico, ela sempre fará tarefas que exijam menos força física, e os homens são os responsáveis, então, por dizer que tipo de trabalho a mecânica tem condição de desempenhar. Há ainda uma contradição no discurso em relação à unidade de sentido III, pois a mulher já pode fazer o mesmo trabalho que o homem. No entanto, volta-se a fazer menção ao trabalho leve como o adequado para as mulheres.

Dessa forma, essas pessoas não percebem a discriminação de gênero, visto que, na prática, estão protegendo a mulher ao lhe designar algo que, em sua mente, elas podem e têm condições de fazer. Todavia, a ação do homem de proteger a mulher remete à questão do estereótipo de fraqueza e fragilidade dela, um segundo sexo. 
Já na análise fenomenológica dos relatos das mulheres, leva-se à emergência de cinco unidades de sentido, sendo essas: (a) Relação com o Trabalho; (b) Relacionamento Interpessoal; (c) Reconhecimento; (d) Postura no ambiente de trabalho; (e) Percepção de Discriminação de Gênero.

Tabela 8

Unidade de Sentido I - Relação com o Trabalho

\begin{tabular}{|c|c|}
\hline Frases & Sujeitos \\
\hline $\begin{array}{l}\text { "Trabalho em uma das melhores empresas do Brasil, com grandes oportunidades de } \\
\text { aprendizagem". }\end{array}$ & M01 \\
\hline \multicolumn{2}{|l|}{ “O salário é bom e trabalho com o que gosto de fazer”. } \\
\hline $\begin{array}{l}\text { "O meu trabalho é importante porque com os meus rendimentos e benefícios consigo pagar minha } \\
\text { faculdade e me sustentar". }\end{array}$ & M02 \\
\hline $\begin{array}{l}\text { "Meu trabalho é importante para mim, pois trabalho fazendo o que gosto e para realizar minhas } \\
\text { necessidades". }\end{array}$ & M03 \\
\hline $\begin{array}{l}\text { "Hoje eu estou tranquila, mas pouco tempo atrás não estava devido ao trabalho monótono que } \\
\text { realizava". }\end{array}$ & M04 \\
\hline $\begin{array}{l}\text { "Muito feliz, pois faço o que gosto, se não gostasse com certeza não estaria trabalhando aqui. Vejo } \\
\text { que dinheiro não é tudo"!!! }\end{array}$ & M05 \\
\hline
\end{tabular}

Nota. Fonte: Relatos de experiência elaborados pelos sujeitos de pesquisa.

A mulher, ao significar sua relação com o trabalho, utiliza palavras como gostar, importante, feliz, tranquilidade, evidenciando que apresenta uma relação mais afetiva. As colaboradoras mostram que se envolvem afetivamente com a tarefa que desenvolvem no ambiente organizacional. Para as mulheres entrevistadas, é preciso ter prazer associado ao trabalho.

Tal unidade remete às discussões efetuadas por Priore (2006), em que as mulheres significam o trabalho ligado a uma atividade prazerosa, enquanto os homens ligam a ação laboral ao reconhecimento de seu papel dominante.

Tabela 9

\section{Unidade de Sentido II - Relacionamento Interpessoal}

\begin{tabular}{lc}
\hline Frases & Sujeitos \\
\hline "Pessoas desonestas, mentirosas, desinteressadas, falta de comprometimento de alguns colegas, & M01 \\
falta de trabalho em equipe, grande demanda de atividades e prazos curtos”. & \\
"Os aspectos de maior relevância no meu trabalho é o relacionamento pessoal com os outros & \\
funcionários da empresa. O trabalho feito pelos meus colegas é de suma importância para o meu & M04 \\
setor, pois se algum deles deixa de fazer o seu trabalho ocorre sobre demanda aos outros & \\
funcionários que no caso deverá absorver a demanda para que volte a se estabilizar”. & M05 \\
"Fazer gestão de pessoas. As pessoas têm suas diferenças como: problemas particulares, criação & \\
diferente, e cada um tem uma maneira diferente para se tratar". &
\end{tabular}

Nota. Fonte: Relatos de experiência elaborados pelos sujeitos de pesquisa.

As mulheres evidenciaram problemas de relacionamento interpessoal como um fator significativo que se processa em seu ambiente de trabalho. Para elas, é difícil relacionar-se com os demais colegas, já que lidam com muitas diferenças. Assim, o trabalho coletivo é um desafio e não uma realidade para as colaboradoras. 
As diferenças residem no fato de a mulher ser, socialmente, atrelada a papéis de mãe e esposa, que devem ser exercidos somente no universo privado. Desse modo, em um universo público, a mulher sempre precisa provar que é capaz de desempenhar uma tarefa. No trabalho organizacional, a mulher parte de um ponto desigual em relação ao homem, pois ele está em seu território de direito, e a mulher está fora do seu papel, sempre tendo que provar capacidade, inteligência, seriedade e prioridades.

Tabela 10

\section{Unidade de Sentido III - Reconhecimento}

Frases

Sujeitos

"Graças a Deus atualmente estou muito feliz com o meu trabalho. Demorou um pouco o reconhecimento, somente após 2 anos de conclusão do curso superior consegui uma promoção e o reconhecimento é mais frequente, não somente com aumento de salário, mas também com reconhecimento pelos serviços realizados de elogios".

"Sim sou feliz, mas espero reconhecimento, faço meu trabalho da melhor maneira possível, pois sei que as empresas não costumam reconhecer muito seus trabalhadores, independente da função que realizamos".

"Sou feliz, pois faço o que gosto, me realizo com meu salário e continuo me qualificando aguardando uma promoção".

"Sim, isso eu vivi pessoalmente, no caso, a funcionária recebeu um reajuste antes de mim por ter mais tempo de casa. E vejo esse quesito nas promoções que ocorrem na empresa".

"O respeito vem da seriedade que você encara seus objetivos e a maneira que você se coloca no meio em que se vive/trabalha".

Nota. Fonte: Relatos de experiência elaborados pelos sujeitos de pesquisa.

O reconhecimento é esperado pelas colaboradoras, o que e um reflexo de que estão desempenhando um trabalho de qualidade. Logo, a promoção é vista como uma forma de legitimação do trabalho feito pelas mulheres.

Conforme visto na unidade anterior, o reconhecimento, para a mulher, representa sua aceitação em um ambiente socialmente pertencente ao homem. O reconhecimento, para a mulher na esfera pública é determinante para que ela siga no movimento de combate às desigualdades entre os gêneros.

Tabela 11

Unidade de Sentido IV - Postura no Ambiente de Trabalho

Frases

Sujeitos

“Às vezes não é questão de preconceito do empregador, algumas mulheres mostram fragilidade e prejudicam contratações futuras de outras mulheres, e talvez não seja pela função, mas pelas próprias características da pessoa (preguiça, força, falta de comprometimento, etc.). Todos os empregados devem mostrar sua capacidade para ser respeitados, independente de ser homem ou mulher, mas em determinadas áreas a mulher deve sim 'mostrar' o seu trabalho e provar que foi efetivada pelo seu esforço/trabalho, e não por ter um caso com o chefe".

"Não, da empresa não percebo diferença de tratamento entre homens e mulheres. Foi muito difícil conseguir e manter esse trabalho".

"Trabalho em turno de revezamento é cansativo e trabalhar a noite requer uma preparação".

"Temos que atuar de forma séria".

"Se a mulher tiver seu profissionalismo, creio que as oportunidades são iguais".

Nota. Fonte: Relatos de experiência elaborados pelos sujeitos de pesquisa. 
Nessa unidade de sentido, evidencia-se a necessidade que as mulheres sentem de mostrar o trabalho e provar a competência para serem respeitadas. E ser profissional significa atuar de forma séria, forte e bastante formal, focando em suas atividades, ou seja, seguindo modelos masculinos. Somente dessa forma, os homens irão vê-las como colegas de trabalho e não como oportunidade de diversão. As mulheres que demonstram fragilidade são mal vistas inclusive por outras mulheres que querem se estabelecer no ambiente de trabalho. Para serem aceitas, as mulheres devem assumir uma postura viril, de força. Logo, o respeito à mulher ocorre se ela se mostra igual ao homem, não havendo valorização pelas diferenças que existem entre os sexos.

Em termos teóricos, tem-se o fenômeno do teto de vidro que aborda as barreiras sutis que travam o avanço de mulheres no ambiente organizacional.

Tabela 12

Unidade de Sentido V - Percepção da Discriminação de Gênero

Frases

Sujeitos

"Mas existe ainda o preconceito para contratar mulheres em algumas tarefas (como operar caminhões e outros equipamentos, mecânica, etc.), e na maioria destas funções os homens são promovidos com maior frequência".

"O fato de eu ser mulher faz com que alguns homens não aceitam que eu faça ou ganhe mais que eles. As mulheres na maioria das vezes quando comento que dirijo caminhão acham o máximo, já os homens falam que não imaginam mulher fazendo esse serviço”.

"Há piadas indiretas, pois o respeito é exigido no trabalho, há preconceito, por ser um trabalho que envolve dirigir, há velho preconceito que mulher dirige pior que homem. Mas de acordo com os mecânicos as mulheres são mais cuidadosas".

"A mulher tem que conquistar seu lugar"!

“A seriedade faz com que a empresa valorize o profissional que ao meu ver não tem sexo".

Nota. Fonte: Relatos de experiência elaborados pelos sujeitos de pesquisa.

Nessa unidade de sentido, observa-se que as mulheres percebem a existência de um preconceito ao seu redor. E, mesmo quando tentam negar isso, como foi o caso da depoente número cinco, há indícios da necessidade inconsciente de superar o preconceito, pois a mulher só é profissional se for séria. Ser séria significa seguir o modelo masculino de comportamento no ambiente de trabalho.

\section{Análise das unidades de sentido}

Diante das análises apresentadas no tópico anterior, apresenta-se uma tabela em que se comparam as unidades de sentido ligadas aos relatos elaborados por homens e mulheres.

Tabela 13

Comparação de Unidades de Sentido

\begin{tabular}{lll}
\hline \multicolumn{1}{c}{ UNIDADES DE SENTIDO } & \multicolumn{1}{c}{ HOMENS } & \multicolumn{1}{c}{ MULHERES } \\
\hline Relação com o trabalho & Racional e Utilitarista & Afetiva \\
& $\begin{array}{l}\text { Realidade; cooperação } \\
\text { masculina; ocorre no processo } \\
\text { Trabalho Coletivo }\end{array}$ & $\begin{array}{l}\text { Desafio; lidar com diferenças; ocorre } \\
\text { entre as pessoas que trabalham }\end{array}$ \\
x Relacionamento Interpessoal & $\begin{array}{l}\text { de trabalho, ou seja, basta que a } \\
\text { função seja complementar. }\end{array}$ & $\begin{array}{l}\text { indepente da função } \\
\text { desempenhada. }\end{array}$ \\
\hline
\end{tabular}




\section{Tabela 13 (continuação)}

\begin{tabular}{|c|c|c|}
\hline UNIDADES DE SENTIDO & HOMENS & MULHERES \\
\hline Reconhecimento & & Legitimação de seu trabalho; \\
\hline $\begin{array}{l}\text { Presença da Mulher x Postura no } \\
\text { Ambiente de Trabalho }\end{array}$ & $\begin{array}{l}\text { Trabalho leve, que exija } \\
\text { cuidado. }\end{array}$ & $\begin{array}{l}\text { seriedade; força; formalidade; } \\
\text { profissionalismo. }\end{array}$ \\
\hline $\begin{array}{l}\text { Ausência x Percepção da } \\
\text { Discriminação de Gênero }\end{array}$ & $\begin{array}{l}\text { Igualdade de tratamento e } \\
\text { oportunidades. }\end{array}$ & $\begin{array}{l}\text { Igualdade de oportunidade e } \\
\text { tratamento para a mulher que adotar } \\
\text { um comportamento masculino. }\end{array}$ \\
\hline
\end{tabular}

Nota. Fonte: elaborado pelos autores.

Conclui-se que as relações de gênero no ambiente de trabalho da mineração são resultado de uma conjuntura de fatores que apresentam, como pano de fundo, a divisão sexual do trabalho; ou seja, mesmo as mulheres estando presentes em ambientes predominantemente masculinos, sempre farão atividades consideradas leves e secundárias.

E a mulher, para combater essa designação preconceituosa, encontra como caminho mais viável negar a si mesma na condição de mulher, comportando-se como homem. Nesse cenário, a mulher pretende ganhar os mesmos espaços que o homem sendo formal, séria, profissional e extremamente focada no trabalho. Isso foi claramente detectado na fala da depoente gestora, que, além de desempenhar seu trabalho, preocupa-se em mostrar seriedade para ser capaz de coordenar uma equipe formada, em sua maioria, por homens. A luta se processa então pela igualdade, sem considerar as diferenças existentes entre homens e mulheres.

Assim, na mineração, a mulher é aceita pelos homens se desempenhar as tarefas leves de forma séria, ou seja, cabe a ela desempenhar atividades secundárias adotando um modelo de comportamento masculino. Logo, mesmo que a mulher ocupe o mesmo cargo que o homem, eles configuram uma forma de dominar suas colegas com base no argumento da força física, como no caso do cargo mecânico de equipamentos. Os homens não veem, portanto, a discriminação de gênero, pois a mulher está ao seu lado fazendo a mesma função, todavia se esquecem de que eles, dentro das tarefas designadas para cada função, têm o poder de dizer quais entre estas a mulher irá desempenhar. A discriminação para eles é mascarada pela presença da mulher, com base no argumento de que elas estão em todos os setores da mineração. Entretanto, não são feitas menções ao número inferior de mulheres, pois estas estão bem distribuídas, dando a impressão de que a empresa apresenta uma política que valorize igualmente os dois sexos.

Mas, para a mulher não é suficiente estar presente no ambiente de trabalho masculino, várias outras conquistas são necessárias. Vale lembrar que, em comparação às percepções de operárias e gestoras, essas mulheres têm anseios similares por reconhecimento e aceitação, embora no cargo de gerência as pressões por comportamentos padronizados ligados à seriedade e a resultados se torne maior. Dessa maneira, o preconceito é sentido pela mulher na proporção em que ela tenha que se adaptar ao meio para ser aceita. Na Figura 1, sintetiza-se a questão. 


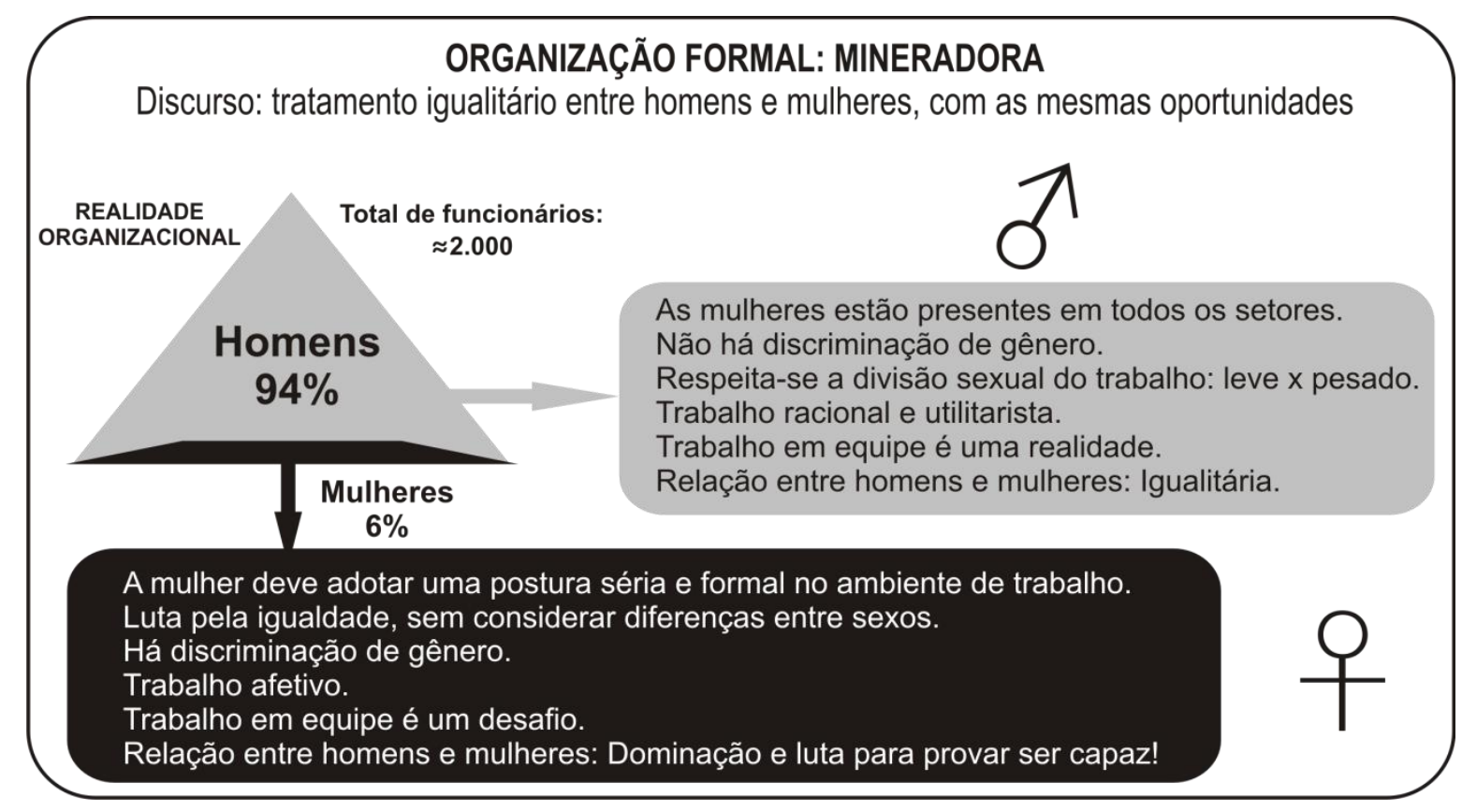

Figura 1. Relações de Gênero no Contexto Organizacional de Empresa de Extração Mineral.

Nota. Fonte: Elaborado pelos autores.

Nesse esquema-síntese, observa-se como o emprego da fenomenologia social permite se aprofundar no processo de significação das relações de gênero por homens e mulheres. Estudando a subjetividade de funcionários consócios de uma empresa de mineração, que vivenciam um constante relacionamento do tipo nós nos encontros face a face, verifica-se como a assimetria de gênero se manifesta sutilmente nessa organização.

Essa é a principal arma da desigualdade de gênero, uma vez que a crença em sua prática tende a ser apresentada pelas organizações e pela sociedade como algo passado, que já não se adapta à realidade contemporânea. Nessa organização, a estratégia para mitigar a desigualdade entre homens e mulheres se dá pela distribuição destas por todos os setores da empresa, dando a impressão de que elas estão presentes e tendo oportunidades iguais em relação aos homens.

\section{Considerações Finais}

No presente trabalho, em sua parte introdutória, objetivou-se desvelar como se processam as relações de gênero no contexto organizacional de uma empresa de extração mineral. Para isso, investigou-se a questão entre funcionários e gestores da área operacional da empresa, cujos dados coletados foram analisados e interpretados a partir da fenomenologia social.

Diante disso, contatou-se que os homens e as mulheres, sujeitos da pesquisa, refletem as relações de gênero em seu ambiente de trabalho de forma diferente, começando pelo processo de significação que ambos atribuem à sua atividade laborativa. Os homens veem o trabalho como um meio, uma oportunidade de atingir outros objetivos, sendo a atividade desempenhada de forma racional e utilitarista. Já as mulheres se envolvem com o trabalho como um processo em desenvolvimento, que representa seu esforço e comprometimento.

Essa percepção reflete ainda a forma de como os sujeitos vislumbram as relações de trabalho, já que, para os homens, o trabalho em equipe é perfeitamente realizado, pois depende fundamentalmente das características das funções que cada um desempenha. Ao passo que a mulher, de forma mais aprofundada, vê o trabalho em equipe como um desafio, na medida em que depende do 
estabelecimento de relações entre pessoas diferentes, ou seja, o trabalho é um envolvimento e, não somente, um conjunto de tarefas.

Em relação ao gênero, os homens, dominantes em quantidade e posições hierárquicas, não detectam nenhum tipo de tratamento desigual entre os sexos. As mulheres estão sempre presente nos ambientes da empresa e desempenham as funções que lhes são cabíveis. Para eles, a presença das mulheres na organização, anteriormente só composta por homens, já representa um sinal de igualdade e de conquista de espaço por parte delas.

Todavia, a mulher percebe a discriminação de gênero em forma de comentários, distribuição de tarefas, concessão de promoções, número de contratação e conjunto de procedimentos que devem adotar. Assim, o fenômeno do teto de vidro é sentido, não na forma de remuneração desigual, mas derivado de um contexto formal e informal que favorece a assimetria de gênero. As colaboradoras almejam muito mais que estarem presentes na organização, pretendendo ascender, ocupando níveis hierárquicos superiores.

Diante disso, o caminho seguido é a adoção de posturas ligadas à força, seriedade e formalidade, pois somente dessa maneira serão aceitas. A mulher que entra na empresa e demonstra fragilidade, recebe hostilidade inclusive por parte de outras mulheres. O pensamento dominante é que a igualdade virá se as mulheres provarem que são fortes e têm condições de fazer qualquer tipo de trabalho. Assim, no ambiente em estudo, as implicações de gênero são visualizadas claramente pelas mulheres, ao contrário dos homens, que julgam que a presença da mulher já garante a elas oportunidade e tratamento igualitário.

Portanto, encerra-se este trabalho evidenciando que a mulher, na mineração, vem conseguindo conquistas, embora tais avanços se devam à sua masculinização, sem existência de respeito e valorização de diferenças. A legitimação do trabalho feminino somente ocorre quanto esse está adequado aos padrões de desempenho masculino. Isso reforça os indicativos da necessidade de se repensar a divisão sexual do trabalho e seus impactos práticos para homens e mulheres.

\section{Artigo recebido em 04.05.2011. Aprovado em 20.12.2011.}

\section{Referências}

Beauvoir, S. (1949). O segundo sexo: fatos e mitos. Rio de Janeiro: Nova Fronteira.

Cappelle, M. C. A., Melo, M. C. O. L. de, Brito, M. J. M., \& Brito, M. J. de. (2004). Uma análise da dinâmica do poder e das relações de gênero no espaço organizacional. RAE Eletrônica, 3(2). Recuperado de http://www.scielo.br/pdf/raeel/v3n2/v3n2a06.pdf. doi: 10.1590/S167656482004000200006

Castilhos, Z. C., \& Castro, N. F. (2006). Mulheres na mineração: restitutio quae sera tamem. [Comunicação Técnica]. Ministério da Ciência e Tecnologia. Rio de Janeiro.

Flick, U. (2009). Desenho da pesquisa qualitativa. Porto Alegre: Artmed.

Gherardi, S., \& Poggio, B. (2001). Creating and recreating gender order in organizations. Journal of World Business, 36(3), 245-259. doi: 10.1016/S1090-9516(01)00054-2

Gibbs, G. (2009). Análise de dados qualitativos. Porto Alegre: Artmed.

Hirata, H. (2002). Nova divisão sexual do trabalho? Um olhar voltado para a empresa e a sociedade. São Paulo: Boitempo. 
Hirata, H., \& Kergoat, D. (2007). Novas configurações da divisão sexual do trabalho. Cadernos de Pesquisa, 37(132), 595-609. doi: 10.1590/S0100-15742007000300005

Martins, J., \& Bicudo, M. (1989). A pesquisa qualitativa em psicologia: fundamentos e recursos básicos. São Paulo: Cortez.

Merleau-Ponty, M. (1994). Fenomenologia da percepção. São Paulo: Martins Fontes.

Minayo, M. C. S. (1998). O desafio do conhecimento. São Paulo: Hucitec-Abrasco.

Novo, M. (2003). La mujer como sujeto, utopia o realidad? Revista Polis, 2(6), 1-15.

Priore, M. Del (Org.). (2006). História das mulheres no Brasil. São Paulo: Contexto.

Quirino, R. (2010, abril). Divisão sexual do trabalho e gênero na mineração. Anais do Congresso Iberamericano de Ciência, Tecnologia e Gênero, Curitiba, PR, Brasil, 8.

Ricoeur, P. (1998). O discurso da acção. Lisboa: Editora 70.

Saffioti, H. I. B. (2004). Gênero e patriarcado: violência contra as mulheres. In G. Venturini, M. Recaman, \& S. Oliveira (Orgs.), A mulher brasileira nos espaços público e privado (pp. 43-59). São Paulo: Editora e Fundação Perseu Abramo.

Sanders, P. (1982). Phenomenology: a new way of viewing organizational research. Academy of Management Review, 7(3), 353-360. doi: 10.2307/257327

Schütz, A. (1972). Fenomenologia del mundo social: introduccion a la sociologia comprensiva. Buenos Aires: Paidos.

Schütz, A. (1979). Fenomenologia e relações sociais. Rio de Janeiro: Zahar Editores.

Soihet, R. (1998). História, mulheres, gênero: contribuições para um debate. In N. Aguiar (Org.), Gênero e ciências humanas: desafio às ciências desde a perspectiva das mulheres (pp. 95-114). Rio de Janeiro: Record e Rosa dos Ventos.

Steil, A. V. (1997). Organizações, gênero e posição hierárquica - compreendendo o fenômeno do teto de vidro. RAUSP, 32(3), 62-69.

Triviños, A. N. S. (1987). Introdução à pesquisa em ciências sociais: a pesquisa qualitativa em educação. São Paulo: Atlas. 